\title{
BMJ Open Mental burden and perception of the study situation among undergraduate students during the COVID-19 pandemic: a cross-sectional study and comparison of dental and medical students
}

Jennifer Guse (D) , ${ }^{1}$ Annabel Susan Weegen, ${ }^{1}$ Ines Heinen, ${ }^{1}$ Corinna Bergelt (D) ${ }^{1,2}$

To cite: Guse J, Weegen AS, Heinen I, et al. Mental burden and perception of the study situation among undergraduate students during the COVID-19 pandemic: a cross-sectional study and comparison of dental and medical students. BMJ Open 2021;11:e054728. doi:10.1136/ bmjopen-2021-054728

- Prepublication history for this paper is available online To view these files, please visit the journal online (http://dx.doi. org/10.1136/bmjopen-2021054728).

JG and ASW contributed equally.

$J G$ and ASW are joint first authors.

Received 21 June 2021 Accepted 12 November 2021

Check for updates

(c) Author(s) (or their employer(s)) 2021. Re-use permitted under CC BY-NC. No commercial re-use. See rights and permissions. Published by BMJ.

${ }^{1}$ Department of Medical Psychology, University Medical Center Hamburg-Eppendorf, Hamburg, Germany

${ }^{2}$ Department of Medical

Psychology, University Medicine Greifswald, Greifswald, Germany

Correspondence to

Dr Jennifer Guse;

j.guse@uke.de

\section{ABSTRACT}

Objectives To investigate levels of distress, depression, anxiety, stress and perception of their current study situation during the COVID-19 pandemic among undergraduate dental and medical students.

Design Observational, cross-sectional study including two consecutive surveys (May and July 2020).

Setting A large medical school in Germany.

Participants All first year dental and medical students were invited. 132 participating first year students (44 dental, 88 medical) from the first survey and 150 students (50 dental, 100 medical) from the second were included in our analyses.

Primary and secondary outcome measures Mental burden (distress thermometer, Patient Health

Questionnaire-4, Perceived Stress Scale-4) and selfreported changes in mental health and perception of study situation during the COVID-19 pandemic (self-developed items) were compared. Open-ended questions were analysed by conventional content analyses.

Results A considerable proportion of students (t1: May 2020: 84.1\%; t2: July 2020: $77.3 \%$ ) reported distress levels above cut-off. In July 2020, dental students reported significantly higher distress scores than medical students (dental: $\mathrm{M}=7.0, \mathrm{SD}=2.3$; medical: $\mathrm{M}=5.7$; $\mathrm{SD}=2.1 ; \mathrm{p}<0.001)$. More dental than medical students reported mild, moderate and severe levels of anxiety and depression symptoms. The majority stated that their mental health and study motivation had not changed during the pandemic. Logistic regression showed that being a dental student was significantly associated with a higher likelihood for serious worries regarding the study situation during COVID-19 at $\mathrm{t} 1$ (OR 4.0; $95 \% \mathrm{Cl} 1.1$ to 14.2). At t2 higher distress was significantly associated with a higher likelihood for experiencing serious worries (OR 1.8; 95\% Cl 1.3 to 2.5). Regarding current concerns related to the pandemic, students most frequently reported difficulties with self-regulated learning (15.2\%), studyrelated worries and uncertainty (14.4\%), missing feedback of students and lecturers (11.4\%) and lack of practical training $(9.8 \%)$.
Strengths and limitations of this study

- This study offers in-depth exploration of students mental health and perception of their study situation during the COVID-19 pandemic by combining quantitative data and qualitative data.

- This study included well-established and valid instruments (quantitative data) and applied conventional content analyses with inductive categorisation (qualitative data).

- Response rates of this study were high $(65.3 \%-87.2 \%)$.

- It is a single-institution study and the cross-sectional design does not allow causal statements about longitudinal developments.

Conclusion The results suggest that high mental burden and the lack of practical training among medical and dental students is an increasing problem, with a possibly even higher urgency in dental students. Tailored psychological and educational support offers during and after the COVID-19 pandemic might help them as they progress through (medical and) dental school.

\section{INTRODUCTION}

The COVID-19 pandemic and its consequences have an impact on the private, professional and social life of all people. ${ }^{1}$ It has brought widespread disruption to undergraduate medical education. ${ }^{23}$ Thus, medical students worldwide face major changes regarding their medical training and study motivation decreased. ${ }^{4}$ Many medical schools have made changes to their curricula and campus life to protect patients and students by social distancing. Roles of medical students' during the COVID-19 pandemic are discussed controversial. ${ }^{5}$ Even in the absence of the COVID-19 pandemic, mental burden 
is common among medical students ${ }^{6-8}$ and several studies report lower mental health outcomes for medical students in the course of their medical studies compared with population reference samples. ${ }^{9}$ In particular, depression and anxiety symptoms are reported among medical ${ }^{710}$ and dental students. ${ }^{11-13}$ Often students feel that they do not have adequate coping strategies to deal with studyrelated workload and stress. ${ }^{14}$ Dental students are highly burdened and perform at a comparable or higher stress level than medical students. ${ }^{15}$ Studies have shown that the stress level increases with each semester, especially due to the high proportion of practical training in dental studies. 1316

In light of novel circumstances during the COVID-19 pandemic, uncertainty relating to personal and professional future and rapid changes dental and medical students may be even more at risk of experiencing severe mental burden during the pandemic than before. Increased incidence rates of stress and mental burden are an expected response under the current conditions. ${ }^{17}$

Studies have shown the negative impact of past pandemics $^{18}$ and the COVID-19 pandemic ${ }^{19}$ on the general population, as well as on specific groups. ${ }^{20}$ Health professionals may be particularly affected, ${ }^{21}$ as pandemicspecific stressors are added to the general ones. ${ }^{22}$ High prevalence for mental health symptoms among healthcare workers exposed to COVID-19 was found. ${ }^{20}$ Students are also highly burdened while facing new challenges raised by the pandemic's consequences. ${ }^{23} 24$ COVID19-related mental stress, higher rates of depression and a high symptom burden from the acute stress response according to the COVID-19 pandemic are common especially among healthcare students, ${ }^{25}$ as they have to cope with mental and emotional issues, including stress and anxiety.

In contrast to the exposure of students in general during the COVID-19 pandemic, the mental burden of medical and dental students in particular is still poorly addressed in the international literature even though they are facing special challenges in healthcare. ${ }^{26}$

Therefore, the aim of this study was to assess the magnitude of distress, depression, anxiety and stress among undergraduate dental and medical students in the course of the COVID-19 pandemic. Second, we aimed to explore students' perception of the study situation during the pandemic and compare dental and medical students' perception during the first lockdown period and thereafter.

\section{METHODS}

\section{Design and setting}

This observational study consists of two cross-sectional surveys conducted at the University Medical Center Hamburg-Eppendorf (UKE), Germany, from 28 May 2020 to 7 June $2020(\mathrm{t} 1)$ and from 16 July 2020 to 31 July 2020 (t2). During this period and before (since mid-March 2020), the German government announced several public health measures to suppress the spread of COVID-19 by increasing social distancing, that is, the closure of schools, daycare, playgrounds and non-essential shops, the prohibition to meet more than one person from another household and depending on regional regulations the prohibition to leave the apartment without reason. ${ }^{27}$ Concurrently lectures and seminars at the universities were predominantly held in a digital format to reduce interpersonal contact and to protect patients, students and faculty. ${ }^{28}$ Thus, the learning environment and examination conditions for students have changed significantly. Many medical schools have discontinued their undergraduate medical training and transitioned most of their teaching to digital formats. ${ }^{29}$ This included but was not limited to the transformation of objective structured clinical examinations ${ }^{30}$ into multiple choice tests.

\section{Participants}

All first year dental students $(n=68)$ enrolled in the integrated dental degree programme iMED DENT launched in 2019 and medical students $(n=352)$ enrolled in the integrated medical degree programme iMED established in 2012 at the Medical School of the University of Hamburg, Germany ${ }^{31}$ were invited to participate in the online surveys. Students were asked to complete an anonymous questionnaire linked to the voluntary curriculum evaluation conducted by the dean's office in regular intervals during the course of the year. A few days in advance the students were informed via e-mail of the study aims, voluntary participation and data protection regulations. Participants did not receive any incentives for answering the questionnaire.

\section{Measures}

We developed an online questionnaire and focused on symptoms of distress, depression, anxiety and stress by using established self-reporting questionnaires. Furthermore, we assessed the perception of the study situation during the pandemic and study motivation with selfdeveloped items. Demographic characteristics (age in categories, gender) were also self-reported.

\section{Distress}

We assessed students' distress at t1 (May 2020) and t2 (July 2020) using the German version of the distress thermometer (DT), a brief screening instrument developed by the National Comprehensive Cancer Network. ${ }^{32}$ The DT is a single-item instrument with a scale from 0 to 10 . Higher scores indicate higher distress. Internationally a cut-off score of 4 is established as a signal that a person is distressed and needs support. The DT is a reliable and efficient screening instrument. ${ }^{32}$

\section{Depression and anxiety}

We measured depression and anxiety using the German version of the four-item Patient Health Questionnaire (PHQ-4), an ultrabrief screening instrument that consists of a two-item depression scale (PHQ-2) and a two-item Generalised Anxiety Disorder scale (GAD-2) ${ }^{33}$ It assesses 
the amount of depression and anxiety symptoms the individual has felt during the past 2 weeks. A score of 3 or higher on the PHQ-2 and GAD-2 is established as a reasonable cut-off score clinically relevant levels of depressive and anxiety symptoms. The total PHQ-4 score is considered as an overall measure of symptom burden with the following categories: 0-2 normal, 3-5 mild, 6-8 moderate, 9-12 severe. It is an efficient screening instrument with good internal consistency and construct validity and areas under the curve between 0.84 (anxiety) and 0.79 (depression) among students. ${ }^{34}$

Changes in mental health and perception of study situation during the COVID-19 pandemic

Furthermore we administered five self-developed items to assess changes in students' mental health and perception of the study situation: Students were asked whether their mental health has changed since the beginning of the pandemic with five answer options (clearly improved; rather improved; unchanged; rather worsened; clearly worsened). They were asked if the assessment of their study situation has changed in the context of the pandemic with three answer options (No, I am as worried or unworried as before; Yes, I am somewhat worried; Yes, I am seriously worried). In addition students were asked if the pandemic affected their possibility to participate in exams with five options to answer (No exams took place since the beginning of the pandemic; Exams took place without changes; Exams did not take place, but a new date is scheduled; Exams did not take place and no new date is scheduled yet; I was not able to attend exams due to quarantine or illness). Students were asked if their study motivation had changed since the beginning of the pandemic. Answers were rated on a 5-point Likert-type scale (clearly increased; rather increased; unchanged; rather decreased; clearly decreased). Finally, students were asked for free text responses regarding the question what currently is occupying them most in their current study situation and what they experience as particularly helpful.

\section{Stress}

In the second survey, students' perception of stress was quantified with the Perceived Stress Scale (PSS-4). The 4-item self-report instrument with reverse coding for two items assesses on a five-point Likert scale the degree to which situations in one's life were perceived as stressful in the past month. ${ }^{35}$ Higher scores on the PSS-4 indicate higher stress levels.

\section{Burdening aspects}

For the second data collection in July 2020, we developed six items based on the qualitative results from the first survey to assess burdening aspects experienced by the students' quantitatively. The respondents had the possibility to answer in four levels ( $1=$ 'not at all burdensome' to 4 = 'very burdensome').

\section{Data analysis}

We matched dental students to medical students according to age and gender in the ratio of 1:2 in order to harmonise the initially inhomogeneous sample sizes and enhance comparability of the samples. In May 2020, the final sample consisted of $\mathrm{n}=132$ students ( 44 dental and 88 medical students). In July 2020, the sample comprised 150 students (50 dental and 100 medical students). With $74 \%$ (t1) and $69 \%$ (t2) female students the gender ratio of the sample is comparable to the ratio of first year students at German medical schools. ${ }^{36}$ We used descriptive statistics to characterise the sample. Group comparisons were carried out using $\chi^{2}$ tests for categorical variables and t-tests for differences of means.

We conducted descriptive analyses to examine the magnitude of DT, depression and anxiety (PHQ-4)

Table 1 Sample characteristics among dental and medical students participating in the first $\left(n_{1}=132\right)$ and second survey $\left(\mathrm{n}_{2}=150\right)$

First survey (May 2020) Second survey (July 2020)

\begin{tabular}{ccccccc}
\hline $\begin{array}{l}\text { Whole sample } \\
(\mathbf{n}=\mathbf{1 3 2})\end{array}$ & $\begin{array}{l}\text { Dental students } \\
\left(\mathbf{n}_{\mathbf{1}}=\mathbf{4 4 )}\right.\end{array}$ & $\begin{array}{l}\text { Medical students } \\
\left(\mathbf{n}_{\mathbf{1}}=\mathbf{8 8}\right)\end{array}$ & $\begin{array}{l}\text { Whole sample } \\
(\mathbf{n}=\mathbf{1 5 0 )}\end{array}$ & $\begin{array}{l}\text { Dental students } \\
\left(\mathbf{n}_{\mathbf{2}}=\mathbf{5 0}\right)\end{array}$ & $\begin{array}{l}\text { Medical } \\
\text { students } \\
\left(\mathbf{n}_{\mathbf{2}}=\mathbf{1 0 0}\right)\end{array}$ \\
\hline$\%$ & $\%$ & $\%$ & $\%$ & $\%$ & $\%$ \\
\hline & $\%$ & & & & \\
\hline 74.8 & 25.0 & 26.1 & 30.7 & 30.0 & 31.0 \\
\hline 7.2 & 75.0 & 73.9 & 69.3 & 70.0 & 69.0
\end{tabular}

\begin{tabular}{|c|c|c|c|c|c|c|}
\hline \multicolumn{7}{|l|}{ Sex: } \\
\hline Male & 25.8 & 25.0 & 26.1 & 30.7 & 30.0 & 31.0 \\
\hline Female & 74.2 & 75.0 & 73.9 & 69.3 & 70.0 & 69.0 \\
\hline \multicolumn{7}{|l|}{ Age } \\
\hline Up to 20 years & 38.6 & 39.7 & 38.6 & 40.0 & 40.0 & 40.0 \\
\hline $21-25$ years & 34.1 & 33.8 & 34.1 & 34.0 & 34.0 & 34.0 \\
\hline $26-30$ years & 18.2 & 17.6 & 18.2 & 18.0 & 18.0 & 18.0 \\
\hline $31-35$ years & 6.8 & 5.9 & 6.8 & 6.0 & 6.0 & 6.0 \\
\hline $\begin{array}{l}\text { Older than } 35 \\
\text { years }\end{array}$ & 2.3 & 2.9 & 2.3 & 2.0 & 2.0 & 2.0 \\
\hline
\end{tabular}


and stress (PSS-4). The results of the entire sample as well as of the subgroups (dental and medical students) were compared with PHQ-4 data of a German medical student sample $(n=321$, mean age $=21.8$ years, $60.7 \%$ women) from a previous study at the same faculty ${ }^{8}$ with one-sample t-tests. To examine the likelihood for serious worries (dichotomous) regarding the study situation during the COVID-19 pandemic at t1 we conducted a binary logistic regression model with sex, subject of study, the magnitude of distress, depression and anxiety as potential predictors. Non-significant variables were excluded via backward elimination and dropped at the level of $\mathrm{p}<0.05$. We applied likelihood ratio method, which is recommended for stepwise methods. ${ }^{37}$ To avoid multicollinearity, we analysed Variable Inflation Factors scores. We conducted effect size calculations and considered according to Cohen's $\mathrm{f}^{2}=0.02$ to be a small effect, $\mathrm{f}^{2}=0.15$ as a medium effect, and $\mathrm{f}^{2}=0.35$ as a large effect. ${ }^{38}$ All quantitative analyses were carried out using IBM SPSS V.27.

We used conventional content analyses with inductive categorisation to analyse the free text responses. ${ }^{39}$ Two researchers familiarised themselves with the qualitative data (IH and JG). They identified key concepts and generated labels of codes for recurring themes independently. Next, both sorted codes into categories independently, which were reviewed by all authors. We developed final definitions for categories and codes with iterative consultations and discussions until consensus was achieved. We chose excerpts to exemplify each category and translated them into English. For the qualitative data analysis, we used MAXQDA 2020 (VERBI Software, 2019).

Following the inductive categorisation, we recoded answers for each category into dichotomous variables (mentioned vs not mentioned) to enhance data transparency and to provide evidence for our interpretation. ${ }^{40}$ When students provided more than one category per response, all responses, respectively, categories were categorised. The qualitative results of the first survey served as the basis for developing six quantitative items for the second survey.

\section{Patient and public Involvement}

We did not involve patients in our study. Research questions were developed by the principal investigators (CB and JG) and discussed with the Curriculumkommitee iMED, Hamburg (CK iMED) in April 2020. CK iMED is a committee consisting of students, teachers and a member of the dean's office, which has the task of further developing and optimising the structure and content of the reformed medical degree programme iMED. Subsequently, all enrolled students were informed by email about the design, conduct, the outcome measures and the recruitment and encouraged to give feedback. After publication a summary of the results will be presented in plain language on the website of the University Medical Center Hamburg-Eppendorf.
RESULTS

Of 68 first year dental students enrolled in the dental education programme at the UKE in May 2020, 44 (65.3\%) completed the first survey (t1) in May 2020 and were matched to 88 medical first year students who completed the $t 1$ survey as described above (overall response rate of the medical students was $87.2 \%$ ). The response rate of the second survey (t2) was $81 \%$ among first year dental students and $82 \%$ among first year medical students. With $75.0 \%$ (t1) and $70.0 \%$ (t2) female dental students and $39.7 \%(\mathrm{t} 1)$ and $40.0 \%$ (t2) aged 20 years and younger, both samples are similar to the population of first year dental students at the faculty. The demographic characteristics of the final samples are shown in table 1.

\section{Distress, depression and anxiety}

Overall, high levels of distress, anxiety and depression were found in both dental and medical students. Compared with a German reference sample ${ }^{41}$ with an overall mean PHQ-4 score of $1.8(\mathrm{SD}=2.0)$ and of 1.5 $(\mathrm{SD}=2.0)$ for a student subsample, our samples reported on average significantly higher anxiety and depression (PHQ-4) scores at t1 and t2: In May 2020, 79.5\% of the dental students and $86.4 \%$ of the medical students reported moderate or severe distress scores and $25.0 \%$ of the dental students and $23.8 \%$ of the medical students reported moderate to severe anxiety and depression scores. In July 2020, dental students reported significantly higher levels of distress and anxiety than medical students (table 2). With regard to gender differences, the scores of male and female students did not differ significantly in the whole sample at $\mathrm{t} 1$ and $\mathrm{t} 2$. However, female dental students (t1: $\mathrm{M}=4.7 ; \mathrm{SD}=2.6 ; \mathrm{t} 2: \mathrm{M}=4.6 ; \mathrm{SD}=2.8$ ) reported significantly higher PHQ-4 scores than male dental students ( $\mathrm{t} 1: \mathrm{M}=2.8 ; \mathrm{SD}=1.5 ; \mathrm{t} 2: \mathrm{M}=2.9 ; \mathrm{SD}=2.6)$ at $\mathrm{t} 1(\mathrm{t}(42)=-2.2, \mathrm{p}=0.031)$ and $\mathrm{t} 2(\mathrm{t}(48)=-2.1, \mathrm{p}=0.043)$.

In July 2020 (t2), dental students reported significantly higher scores of distress and anxiety than medical students, while both groups were comparable with regard to their overall anxiety and depression symptom burden (24.0\% with moderate or severe symptoms in dental students, $19.0 \%$ in medical students). With regard to self-perceived stress (only assessed in the second survey), dental students reported higher stress levels than medical students (table 2).

\section{Changes in mental health and perception of the study situation}

Overall, about one-third of the students $(36.4 \%$ dental students vs $29.5 \%$ medical students) reported that their mental health had worsened because of the pandemic at t1. Likewise, a total of $35.6 \%(45.5 \%$ dental vs $30.7 \%$ medical students) reported a decrease in their study motivation at $\mathrm{t} 1$ and $36.7 \%$ at $\mathrm{t} 2(36.0 \%$ dental vs $37.0 \%$ medical students). With regard to worries about the current study situation more medical students (t1: 46.4\%; t2: $47.5 \%$ ) than dental students (t1: $31.8 \%$; 2 : $34.7 \%$ ) reported to be unperturbed and slightly more dental 


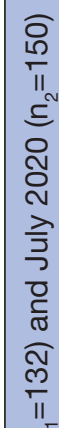

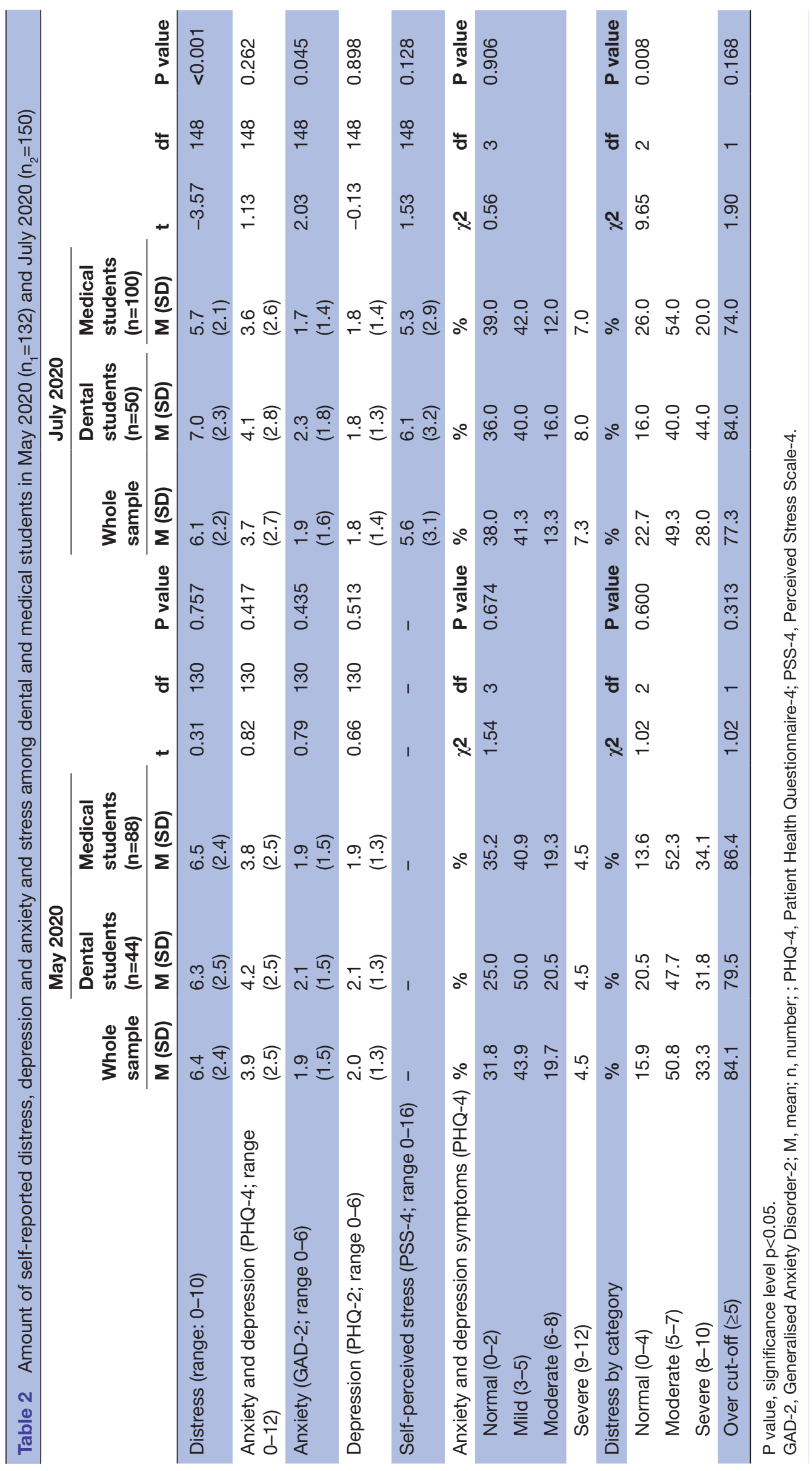




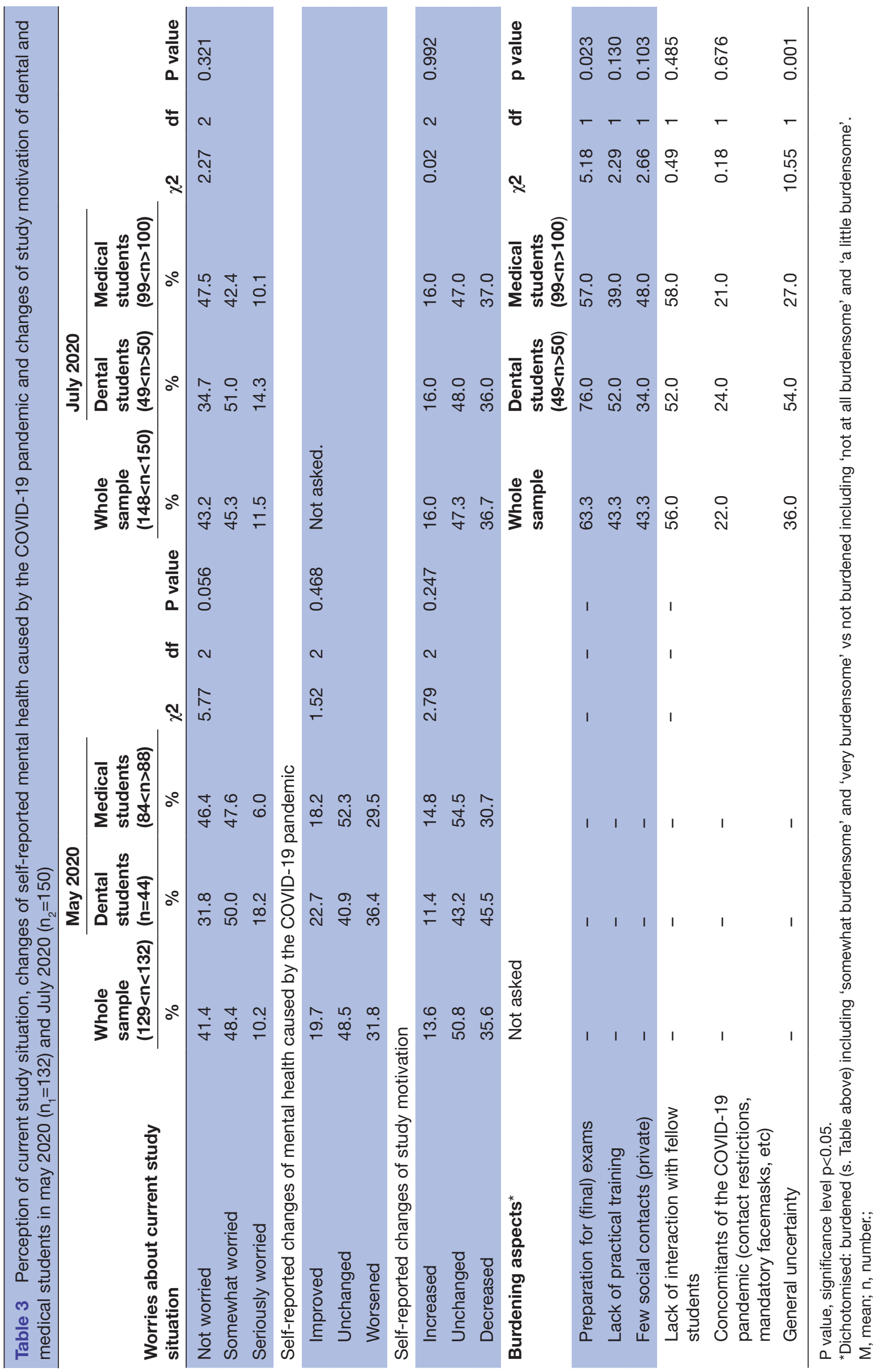


Table 4 Binary logistic regression models on the association of study subject, depression and distress with serious worries in dental and medical students during the COVID-19 pandemic

\begin{tabular}{|c|c|c|c|c|}
\hline May 2020 & OR & $95 \% \mathrm{Cl}$ & P value & Effect size* \\
\hline \multicolumn{5}{|l|}{ Subject of study } \\
\hline Dental & 4.0 & & n.a. & 0.032 \\
\hline Distress thermometer (DT) & 1.4 & 0.9 to 1.9 & 0.078 & \\
\hline Depression symptoms (PHQ-2) & 1.5 & 0.9 to 2.6 & 0.091 & \\
\hline DT & 1.8 & 1.3 to 2.5 & 0.001 & 0.24 \\
\hline
\end{tabular}

${ }^{*}$ According to Cohen's guidelines (1988) we considered $f^{2}=0.02$ to be a small effect, $f^{2}=0.15$ as a medium effect, and $f^{2}=0.35$ as a large effect.

PHQ, Patient Health Questionnaire.

than medical students were seriously worried at t1 $(18.2 \%$ vs $6.0 \%)$ and at t2 (14.3\% vs $10.1 \%)$. However, in both surveys dental and medical students did not differ statistically significant regarding their self-reported changes of mental health, study motivation or worries about the current study situation (table 3). Likewise, we did not find statistically significant differences between male and female students.

\section{Burdening aspects}

Many of students felt burdened due to the lack of interaction with fellow students. In comparison to medical students, significantly more dental students stated that they were burdened with regard to the exams and the general uncertainty (table 3).

Binary logistic regression indicated that dental students (O: $4.0 ; 95 \%$ CI 1.1 to 14.2 ) were significantly more likely to experience serious worries regarding the current study situation during COVID-19 than medical students in May 2020. In July 2020 higher distress (OR 1.8; 95\% CI 1.3 to 2.5) was associated with a higher likelihood for reporting serious worries regarding the current study situation during COVID-19 (table 4).

Table 5 Categories, examples and quantified responses by category for the questions 'what is currently occupying you most in your current study situation?' in May $2020(n=132)$

\begin{tabular}{|c|c|c|c|c|c|c|c|}
\hline \multicolumn{2}{|c|}{ What is currently occupying you most? } & \multirow{2}{*}{$\begin{array}{l}\begin{array}{l}\text { Whole } \\
\text { sample } \\
(\mathrm{n}=132)\end{array} \\
\text { mentioned } \\
\%\end{array}$} & \multirow{2}{*}{$\begin{array}{l}\begin{array}{l}\text { Dental } \\
\text { students } \\
(n=44)\end{array} \\
\text { mentioned } \\
\%\end{array}$} & \multirow{2}{*}{$\begin{array}{l}\begin{array}{l}\text { Medical } \\
\text { students } \\
(\mathrm{n}=88)\end{array} \\
\text { mentioned } \\
\%\end{array}$} & \multirow[b]{2}{*}{$\chi^{2}$} & \multirow[b]{2}{*}{ df } & \multirow[b]{2}{*}{$P$ value } \\
\hline $\begin{array}{l}\text { Category and } \\
\text { subcategory }\end{array}$ & Example & & & & & & \\
\hline $\begin{array}{l}\text { Difficulties with self- } \\
\text { regulated learning } \\
(\mathrm{n}=20 ; 15.2 \%) \\
\text { Self-motivation } \\
\text { Difficulties with new } \\
\text { learning environment }\end{array}$ & $\begin{array}{l}\text { 'Self-motivation- the exchange with fellow students and lecturers is } \\
\text { missing, and therefore one has to motivate oneself every day anew to } \\
\text { sit down at home (the library as a room for studying is also missing) } \\
\text { and to motivate oneself to nevertheless 'attend' all study courses in } \\
\text { time and to catch up on the study-work.' } \\
\text { 'Since I don't have the proper learning environment at home, I } \\
\text { found it difficult to learn the very extensive content in an appropriate } \\
\text { manner.' }\end{array}$ & 15.2 & 15.9 & 14.8 & 0.03 & 1 & 0.864 \\
\hline $\begin{array}{l}\text { Study-related worries } \\
\text { and uncertainty } \\
\text { ( } n=19 ; 14.4 \%) \\
\text { Concerns to perform } \\
\text { worse/to fail } \\
\text { Study-related } \\
\text { uncertainty }\end{array}$ & $\begin{array}{l}\text { 'Extreme pressure to teach myself the mass of content in a short time } \\
\text { through e-learning in order to succeed on the exam.' } \\
\text { 'The uncertainty of if and when face-to-face classes can be held } \\
\text { again, and if potentially my study time will be extended due to this } \\
\text { pandemic.' }\end{array}$ & 14.4 & 20.5 & 11.4 & 1.97 & 1 & 0.161 \\
\hline $\begin{array}{l}\text { Lack of feedback from } \\
\text { other students and } \\
\text { lecturers } \\
(n=15 ; 11.4 \%)\end{array}$ & $\begin{array}{l}\text { 'Due to the online format, the exchange with fellow students and the } \\
\text { lecturers is missing. (...).' }\end{array}$ & 11.4 & 11.4 & 11.4 & 0.00 & 1 & 1.000 \\
\hline $\begin{array}{l}\text { Lack of practical training } \\
(\mathrm{n}=13 ; 9.8 \%)\end{array}$ & $\begin{array}{l}\text { 'The practical components in dental education are essential and (...) } \\
\text { are now being cancelled. (...)' }\end{array}$ & 9.8 & 20.5 & 4.5 & 8.36 & 1 & 0.004 \\
\hline $\begin{array}{l}\text { Other } \\
(n=9 ; 6.8 \%)\end{array}$ & $\begin{array}{l}\text { 'Lack of available childcare. Learning with (...) children at home is a } \\
\text { challenge.' }\end{array}$ & 6.8 & 11.4 & 4.5 & 2.15 & 1 & 0.143 \\
\hline
\end{tabular}

$P$ value, significance level $p<0.05$.

n, number. 
Table 6 Categories, examples and quantified responses by category for the questions 'what do you currently experience as particularly helpful?' in May 2020 ( $n=132)$

\begin{tabular}{|c|c|c|c|c|c|c|c|}
\hline \multicolumn{2}{|c|}{ What do you currently experience as particularly helpful? } & $\begin{array}{l}\text { Whole } \\
\text { sample } \\
\text { (n=132) } \\
\text { mentioned } \\
\%\end{array}$ & $\begin{array}{l}\begin{array}{l}\text { Dental } \\
\text { students } \\
(\mathrm{n}=44)\end{array} \\
\text { mentioned } \\
\%\end{array}$ & $\begin{array}{l}\begin{array}{l}\text { Medical } \\
\text { students } \\
(\mathbf{n}=88)\end{array} \\
\text { mentioned } \\
\%\end{array}$ & $\chi^{2}$ & df & P value \\
\hline $\begin{array}{l}\text { Exchange with } \\
\text { students and } \\
\text { lecturers } \\
(n=18 ; 13.6 \%)\end{array}$ & $\begin{array}{l}\text { 'Intensive exchange with fellow students } \\
\text { and lecturers.' }\end{array}$ & 13.6 & 15.9 & 12.5 & 0.29 & 1 & 0.591 \\
\hline $\begin{array}{l}\text { Flexibility due to } \\
\text { online lessons } \\
(n=17 ; 12.9 \%)\end{array}$ & $\begin{array}{l}\text { 'The online semester also brings many } \\
\text { advantages. You can arrange everything } \\
\text { yourself and work at your own pace. This } \\
\text { also takes away a lot of stress for me } \\
\text { personally (...)' }\end{array}$ & 12.9 & 15.9 & 11.4 & 0.54 & 1 & 0.462 \\
\hline $\begin{array}{l}\text { Balance through } \\
\text { sports and leisure } \\
(\mathrm{n}=11 ; 8.3 \%)\end{array}$ & $\begin{array}{l}\text { 'The fact that I can do my team sports } \\
\text { again, that gives me enough variety and } \\
\text { distraction' }\end{array}$ & 8.3 & 11.4 & 6.8 & 0.79 & 1 & 0.373 \\
\hline $\begin{array}{l}\text { Other } \\
(n=9 ; 6.8 \%)\end{array}$ & 'Encouragement of friends and family' & 6.8 & 9.1 & 5.7 & 0.54 & 1 & 0.464 \\
\hline
\end{tabular}

$P$ value, significance level $p<0.05$.

$\mathrm{n}$, number.

\section{Current concerns and helpful aspects}

A total of 52 students (39.4\%) provided optional free-text responses regarding the question 'What is currently occupying you most in your current study situation?'. We identified five categories in a multistage inductive process. The most frequent categories were 'difficulties with self-regulated learning and self-motivation', followed by 'study-related worries and uncertainty', 'lack of feedback from other students and lecturers' and 'lack of practical training'. Significantly more dental $(20.5 \%)$ than medical students $(4.5 \%)$ reported concerns about the lack of practical training $\left(\chi^{2}=8.4 ; \mathrm{df}=1 ; \mathrm{p}=0.004\right)$ (table 5$)$.

Furthermore, 53 students $(40.2 \%)$ completed optional free-text responses to the question 'What do you currently experience as particularly helpful?'. Again five categories were identified through a multistep inductive process. The most common categories were 'Exchange with other students and lecturers', followed by 'flexibility due to online lessons', 'self-regulation, self-motivation and selfstructuring', and 'balance through sports and leisure'. Dental and medical students did not differ significantly in their answers with regard to helpful aspects (table 6).

\section{DISCUSSION}

This study investigated the mental burden and study situation among undergraduate dental and medical students after the initial stage of the COVID-19 pandemic from May 2020 to July 2020. In line with previous studies conducted before the pandemic dental and medical students reported high levels of distress, anxiety and depression. ${ }^{8} 1242$ Compared with the norm population students of both professions reported significantly higher levels of anxiety and depression, consistent with findings of other studies. ${ }^{8}{ }^{43}$ In light of the COVID-19 pandemic, the presence of additional pandemic-specific stressors is likely. ${ }^{22}$ A recent study showed that for most students isolation from student social networks is associated with increased anxiety levels. ${ }^{24}$ According to our qualitative data, the lack of direct contact with fellow students, which could only take place via online media, affects both student professions negatively. These findings complement a recent empirical study in which undergraduate medical students reported lack of interactions with peers, faculty and patients in practice as negative aspects of digital teaching. ${ }^{44}$ For dental students, the lack of practical training played a major role, as dentists usually take dental courses from the first semester onwards to learn the practical skills from early stage on. ${ }^{45}$ In comparison, this issue does not yet affect medical students as much in the early stages of their studies, as the undergraduate medical curriculum in Germany includes fewer practical training during this time. ${ }^{46}$ In sum this probably accounts for our findings that reported levels of anxiety and depression are even higher than among students of the same medical school prior to the Corona pandemic. ${ }^{8}$

With regard to the study situation, medical and in particular dental students were concerned about their current study situation. This trend continued in the further course 
of the pandemic. These results corroborate recent findings in a representative sample in Austria with a notable decline in mental health during the pandemic. ${ }^{47}$

In line with the findings of Stangvaltaite-Mouhat et al female dental students showed more pronounced anxiety symptoms than male dental students in our study. ${ }^{11}$ This underlines that mental burden may be higher among female students in general. ${ }^{48}$ Recent studies also suggest that women are particular burdened during the COVID-19 pandemic. ${ }^{47}{ }^{49-52}$ Furthermore several studies showed that certain age groups, including individuals between 18 and 25 years - the most common age group in students - suffered more from mental distress. 47495153 Qiu et al suspect social media to be one of the causes. ${ }^{49}$ Previous research seems to confirm this hypothesis as younger people tend to receive a large amount of information via social media, which can easily trigger stress. ${ }^{54}$ The easy accessibility and constant presence of pandemic information may lead to an increase in the duration of information consumption. This increasing duration reinforces the potential negative influence on mental health. ${ }^{55}$ A noteworthy finding is that dental students reported increased levels of distress, anxiety and more worries in the second survey whereas medical students' scores were slightly lower at the second survey.

There are some limitations of our study. The crosssectional surveys at two different times do not allow causal statements about longitudinal developments. Another limitation is the univariate nature of the analysis conducted. The univariate model is less comprehensive compared with multivariate models and does not consider the potential influence of other factors. The small sample size limits representativeness. However, due to the high response rates $(65 \%-87 \%$ in the first and $81 \%-82 \%$ in the second survey) one may assume that a majority of the respondents participated in both surveys. Thus, these single-institutional and cross-sectional surveys achieve a high level of comparability and representativeness. Still there was a considerable proportion of students that did not participate in the surveys, which might lead to a volunteer bias. ${ }^{56}$ Non-volunteers may encompass students who suffer from high levels of distress, anxiety and/or depression. Thus some of the parameters reported in the study may be underestimating the true burden.

Furthermore, no comparisons can be made with the situation before the outbreak of the pandemic, among the same population. Nevertheless, the study by Heinen et al conducted at the same medical school with the same measures serves as a valid context to frame our findings. ${ }^{8}$

Considering the worsened levels of psychological distress among students during the COVID-19 pandemi ${ }^{5758}$ academic institutions should provide timely services in terms of tailored interventions, which address the specific worries of dental and medical students. Other authors already provided valuable and concrete recommendations how to reduce the impact of COVID-19 on student-athlete mental health. ${ }^{59} 60$ Grubic et al proposed a framework to manage student-athlete mental health during the pandemic including 'goal setting/motivation' and 'support system/social network' as potential positive influencers. These aspects could be addressed by medical schools in the form of mentoring. Mentoring was identified as valuable intervention for undergraduate medical students due to its association with improved emotional well-being of students before the pandemic. ${ }^{61}$ During the pandemic, a novel near-peer mentoring intervention via social media was reported with promising first results. ${ }^{62}$ Thus, the implementation of mentoring at medical schools or the transfer of existing mentoring interventions digital formats might help to reduce the negative impact of the COVID-19 pandemic on dental and medical students. At the same time, longitudinal research is needed to monitor the mental health of students during the pandemic and after as well as rigour evaluation of all interventions.

\section{Conclusion}

Overall students of medicine and dentistry are particularly affected by high mental distress and burden due to the demanding contents and structure of their studies. It is likely that the concomitant symptoms of the pandemic have an additional negative impact on the levels of stress, anxiety and depression of the students.

Especially dental students reported higher levels of burden which might be associated with the high practical content early in their studies. The increase in anxiety levels of dental students might be associated with the duration of the restrictions of especially the practical content during the undergraduate study. Against this background, further monitoring of both dental and medical students during the pandemic would be important in order to develop and introduce tailored prevention concepts adapted to the specific study situation.

Correction notice This article has been corrected since it was first published. The authors Annabel Susan Weegen and Jennifer Guse contributed equally to the article (shared first authorship).

Acknowledgements We would like to thank all students who participated in the study and the evaluation team of the faculty who administered the online survey.

Contributors JG designed the study and contributed to the analysis and interpretation of the data. She critically revised the manuscript during the internal revision process and wrote continuing drafts as well as the final draft of the manuscript. ASW analysed the data and contributed to the interpretation of the data. She wrote the first draft of the manuscript and critically revised the manuscript during the internal revision process. IH contributed to the analysis and interpretation of the data. She was involved in drafting the article and critically revised the manuscript during the internal revision process. CB designed the study, analysed the data and contributed to the interpretation of the data. She wrote the first draft of the manuscript and critically revised the manuscript during the internal revision process. $\mathrm{CB}$ is responsible for the overall content as the guarantor. All authors gave their final approval of the version to be published and agree to be accountable for all aspects of the work in ensuring that questions related to the accuracy or integrity of any part of the work are appropriately investigated and resolved.

Funding The authors have not declared a specific grant for this research from any funding agency in the public, commercial or not-for-profit sectors.

Competing interests None declared. 
Patient and public involvement Patients and/or the public were involved in the design, or conduct, or reporting, or dissemination plans of this research. Refer to the Methods section for further details.

Patient consent for publication Not applicable.

Ethics approval Institutional ethical approval was obtained from the local ethics board of the Center for Psychosocial Medicine at the University Medical Center Hamburg-Eppendorf, approval number LPEK-0161, prior to commencement of this research. Only students who provided informed consent were able to participate in the study.

\section{Provenance and peer review Not commissioned; externally peer reviewed.}

Data availability statement № additional data are available. As ethical approval was not obtained to make data sharing possible outside of the listed research team.

Open access This is an open access article distributed in accordance with the Creative Commons Attribution Non Commercial (CC BY-NC 4.0) license, which permits others to distribute, remix, adapt, build upon this work non-commercially, and license their derivative works on different terms, provided the original work is properly cited, appropriate credit is given, any changes made indicated, and the use is non-commercial. See: http://creativecommons.org/licenses/by-nc/4.0/.

\section{ORCID iDs}

Jennifer Guse http://orcid.org/0000-0001-5020-929X

Corinna Bergelt http://orcid.org/0000-0003-1413-1872

\section{REFERENCES}

1 Vindegaard N, Benros ME. COVID-19 pandemic and mental health consequences: systematic review of the current evidence. Brain Behav Immun 2020;89:531-42.

2 Empfehlungen II Der Deutschen Hochschulmedizin zum Studium Der Humanmedizin und Zahnmedizin während Der aktuellen COVID-19-Pandemie, 18.03.2020.: Verband Der Universitätsklinika Deutschlands und MFT Medizinischer Fakultätentag, 2020. Available: https://www.uniklinika.de/fileadmin/user_upload/Covid19-Empfehlungen_DHM_zum_Medizinstudium_2020-03-18.pdf [Accessed 8 Jun 2020].

3 Whelan A, Prescott J, Young G. Guidance on Medical Students' Clinical Participation: Effective Immediately.: Association of American Academic Colleges, 2020. Available: https://lcme.org/wp-content/ uploads/filebase/March-17-2020-Guidance-on-Mediical-StudentsClinical-Participation.pdf [Accessed 8 Jun 2020].

4 Guse J, Heinen I, Kurre J, et al. Perception of the study situation and mental burden during the COVID-19 pandemic among undergraduate medical students with and without mentoring. GMS J Med Educ 2020;37:Doc72.

5 Miller DG, Pierson L, Doernberg S. The role of medical students during the COVID-19 pandemic. Ann Intern Med 2020;173:145-6.

6 Bacchi S, Licinio J, Schwenk TL, Davis L, Wimsatt LA. Resilience and psychological distress in psychology and medical students. Acad Psychiatry 2017;41:185-8.

7 Hope V, Henderson M. Medical student depression, anxiety and distress outside North America: a systematic review. Med Educ 2014;48:963-79.

8 Heinen I, Bullinger M, Kocalevent R-D. Perceived stress in first year medical students - associations with personal resources and emotional distress. BMC Med Educ 2017; 17:4

9 Knipe D, Maughan C, Gilbert J, et al. Mental health in medical, dentistry and veterinary students: cross-sectional online survey. BJPsych Open 2018;4:441-6.

10 Puthran R, Zhang MWB, Tam WW, et al. Prevalence of depression amongst medical students: a meta-analysis. Med Educ 2016;50:456-68.

11 Stangvaltaite-Mouhat L, Pūrienė A, Chałas R, et al. Self-Reported psychological problems amongst undergraduate dental students: a pilot study in seven European countries. Eur J Dent Educ 2020;24:341-50.

12 Basudan S, Binanzan N, Alhassan A, Depression AA. Depression, anxiety and stress in dental students. Int J Med Educ 2017;8:179-86.

13 Bathla M, Singh M, Kulhara P, et al. Evaluation of anxiety, depression and suicidal intent in undergraduate dental students: a crosssectional study. Contemp Clin Dent 2015;6:215-22.

14 Jurkat H, Höfer S, Richter L, et al. [Quality of life, stress management and health promotion in medical and dental students. A comparative study]. Dtsch Med Wochenschr 2011;136:1245-50.

15 Harris RC, Millichamp CJ, Thomson WM. Stress and coping in fourth-year medical and dental students. N Z Dent J 2015;111:102-8.
16 Astill S, Ricketts N, Singh L-A, et al. Environmental and perceived stress in Australian dental undergraduates: preliminary outcomes. J Dent Res Dent Clin Dent Prospects 2016;10:270-9.

17 Petzold MB, Plag J, Ströhle A. [Dealing with psychological distress by healthcare professionals during the COVID-19 pandemia]. Nervenarzt 2020;91:417-21.

18 Hawryluck L, Gold WL, Robinson S, et al. Sars control and psychological effects of quarantine, Toronto, Canada. Emerg Infect Dis 2004;10:1206-12.

19 Wang C, Pan R, Wan X, et al. Immediate psychological responses and associated factors during the initial stage of the 2019 coronavirus disease (COVID-19) epidemic among the general population in China. Int J Environ Res Public Health 2020;17. doi:10.3390/ijerph17051729. [Epub ahead of print: 0603 2020].

20 Lai J, Ma S, Wang Y, et al. Factors associated with mental health outcomes among health care workers exposed to coronavirus disease 2019. JAMA Netw Open 2020;3:e203976.

21 Bao Y, Sun Y, Meng S, et al. 2019-nCoV epidemic: address mental health care to empower Society. Lancet 2020;395:e37-8.

22 Inter-Agency Standing Committee (IASC). IASC guidance on operational considerations for Multisectoral mental health and psychosocial support programmes during the COVID-19 pandemic IASC guidance on operational considerations for Multisectoral MHPSS programmes during the COVID-19 Pandemic.pdf, 2020.

23 Odriozola-González P, Planchuelo-Gómez Álvaro, Irurtia MJ, et al. Psychological effects of the COVID-19 outbreak and lockdown among students and workers of a Spanish university. Psychiatry Res 2020;290:113108.

24 Elmer T, Mepham K, Stadtfeld C. Students under lockdown: comparisons of students' social networks and mental health before and during the COVID-19 crisis in Switzerland. PLoS One 2020;15:e0236337.

25 Li Y, Wang Y, Jiang J, et al. Psychological distress among health professional students during the COVID-19 outbreak. Psychol Med 2021;51:1-3.

26 O'Byrne L, Gavin B, McNicholas F. Medical students and COVID-19: the need for pandemic preparedness. J Med Ethics 2020;46:623-6.

27 Steinmetz H, Batzdorfer V, Bosnjak M. Data from: the ZPID lockdown measures dataset. ZPID Science Information 2020;20. doi:10.23668/ psycharchives.3019

28 Berlin: HRK German Rectors' conference. Available: https://www.hrk de/activities/the-covid-19-pandemic-and-the-german-universities/ [Accessed 29 Jul 2020].

29 Rose S. Medical student education in the time of COVID-19. JAMA 2020;323:2131. doi:10.1001/jama.2020.5227

30 Gerhard-Szep S, Güntsch A, Pospiech P, et al. Assessment formats in dental medicine: an overview. GMS J Med Educ 2016;33:Doc65.

31 Rheingans A, Soulos A, Mohr S, et al. The Hamburg integrated medical degree program iMED. GMS J Med Educ 2019;36:Doc52.

32 Mehnert A, Müller D, Lehmann C. Die Deutsche version des NCCN Distress-Thermometers: Empirische Prüfung eines Screening-Instruments Zur Erfassung psychosozialer Belastung bei Krebspatienten. Zeitschrift für Psychiatrie Psychologie und Psychotherapie 2006;54:213-23. doi:10.1024/1661-4747.54.3.213

33 Kroenke K, Spitzer RL, Williams JBW, et al. An ultra-brief screening scale for anxiety and depression: the PHQ-4. Psychosomatics 2009;50:613-21.

34 Khubchandani J, Brey R, Kotecki J, et al. The psychometric properties of PHQ-4 depression and anxiety screening scale among college students. Arch Psychiatr Nurs 2016;30:457-62.

35 Cohen S, Kamarck T, Mermelstein R. A global measure of perceived stress. J Health Soc Behav 1983;24:385-96.

36 Studierende: Deutschland, Semester, Nationalität, Geschlecht, Studienfach. Available: https://www-genesis.destatis.de/genesis/ online?operation $=$ previous\&levelindex $=1 \&$ step $=1$ \&titel=Ergebnis \& levelid=1616753759559\&acceptscookies=false\#abreadcrumb [Accessed 26 Mar 2021]

37 Field A. Discovering statistics using IBM SPSS statistics : and sex and drugs and rock ' $n$ ' roll. 4th ed. Los Angeles: Sage, 2013.

38 Cohen J. Statistical power analysis for the behavioral sciences. 2nd ed. Hillsdale, NJ: Erlbaum, 1988.

39 Hsieh H-F, Shannon SE. Three approaches to qualitative content analysis. Qual Health Res 2005;15:1277-88.

40 Monrouxe LV, Rees CE. When I say ... quantification in qualitative research. Med Educ 2020;54:186-7.

41 Löwe B, Wahl I, Rose M, et al. A 4-item measure of depression and anxiety: validation and standardization of the patient health Questionnaire-4 (PHQ-4) in the general population. J Affect Disord 2010;122:86-95. 
42 Jiménez-Ortiz JL, Islas-Valle RM, Jiménez-Ortiz JD, et al. Emotional exhaustion, burnout, and perceived stress in dental students. $J$ Int Med Res 2019;47:4251-9.

43 Stormon N, Ford PJ, Kisely S, et al. Depression, anxiety and stress in a cohort of Australian dentistry students. Eur J Dent Educ 2019;23:507-14.

44 Mohr S, Küfe B, Rheingans A, et al. Attitude towards and adoption of the novel learning environment among undergraduate medical students during COVID-19. Front Educ 2021;6:714526.

45 Mekhemar M, Conrad J, Attia S, et al. Oral health attitudes among preclinical and clinical dental students in Germany. Int J Environ Res Public Health 2020;17:4253.

46 Chenot J-F. Undergraduate medical education in Germany. Ger Med Sci 2009;7:Doc02.

47 Dale R, Budimir S, Probst T, et al. Mental health during the COVID-19 Lockdown over the Christmas period in Austria and the effects of sociodemographic and lifestyle factors. Int J Environ Res Public Health 2021;18. doi:10.3390/ijerph18073679. [Epub ahead of print: 0104 2021].

48 Dyrbye LN, Thomas MR, Shanafelt TD. Systematic review of depression, anxiety, and other indicators of psychological distress among U.S. and Canadian medical students. Acad Med 2006;81:354-73.

49 Qiu J, Shen B, Zhao M, et al. A nationwide survey of psychological distress among Chinese people in the COVID-19 epidemic: implications and policy recommendations. Gen Psychiatr 2020;33:e100213.

50 Park CL, Russell BS, Fendrich M, et al. Americans' COVID-19 stress, coping, and adherence to CDC guidelines. J Gen Intern Med 2020;35:2296-303.

51 Liu N, Zhang F, Wei C, et al. Prevalence and predictors of PTSS during COVID-19 outbreak in China hardest-hit areas: gender differences matter. Psychiatry Res 2020;287:112921.
52 Pieh C, Budimir S, Probst T. The effect of age, gender, income, work, and physical activity on mental health during coronavirus disease (COVID-19) lockdown in Austria. J Psychosom Res 2020:136:110186. doi:10.1016/j.jpsychores.2020.110186

53 Brooks SK, Webster RK, Smith LE, et al. The psychological impact of quarantine and how to reduce it: rapid review of the evidence. Lancet 2020;395:912-20.

54 Gabriel R, Röhrs HP. Social media: Springer Gabler, 2017.

55 Huang Y, Zhao N. Generalized anxiety disorder, depressive symptoms and sleep quality during COVID-19 outbreak in China: a web-based cross-sectional survey. Psychiatry Res 2020;288:112954.

56 Salkind NJ. Encyclopedia of research design. Thousand Oaks, CA: SAGE Publications, 2010.

57 Cao W, Fang Z, Hou G, et al. The psychological impact of the COVID-19 epidemic on college students in China. Psychiatry Res 2020;287:112934.

58 Zhang $\mathrm{Y}$, Zhang $\mathrm{H}$, Ma X, et al. Mental health problems during the COVID-19 pandemics and the mitigation effects of exercise: a longitudinal study of college students in China. Int J Environ Res Public Health 2020;17:3722.

59 Grubic N, Badovinac S, Johri AM. Student mental health in the midst of the COVID-19 pandemic: a call for further research and immediate solutions. Int J Soc Psychiatry 2020;66:517-8.

60 Grubic N, Jain S, Mihajlovic V, et al. Competing against COVID-19: have we forgotten about student-athletes' mental health? $\mathrm{Br} J$ Sports Med 2021;55:950-1.

61 Wasson LT, Cusmano A, Meli L, et al. Association between learning environment interventions and medical student well-being: a systematic review. JAMA 2016;316:2237-52.

62 Rastegar Kazerooni A, Amini M, Tabari P, et al. Peer mentoring for medical students during the COVID-19 pandemic via a social media platform. Med Educ 2020;54:762-3. 